\title{
TRANS-ATLANTYK DE WITOLD GOMBROWICZ, GUIA DE LECTURA PER A NO-POLONESOS
}

\author{
PAU FREIXA TERRADAS \\ Universitat de Barcelona \\ paufreixa@ub.edu
}

RESUM

Witold Gombrowicz arribà a Buenos Aires a bord del vaixell Chrobry el 22 d'agost de 1939. Uns dies després l'Alemanya nazi envaïa Polònia i Gombrowicz decidia quedar-se a l'Argentina, on romandria gairebé 24 anys. L'any 1947, després d'haver passat gairebé 10 anys sense escriure pràcticament res, decideix explicar la seva atípica arribada al país i les setmanes que seguiren. Però aquell Trans-Atlantyk ràpidament agafarà una altra destinació i retornarà l'autor cap a la seva terra nativa, convertint-se en una complexa al·legoria sobre la relació entre individu i nació. Per a fer-ho tot més difícil Gombrowicz escull una forma d'expressió literària provinent dels llibres de memòries que escrivien els nobles sàrmates al segle XVII. Tot i que el fil argumental de la novel·la transcorre a l'Argentina, el tema principal acabarà sent Polònia. Tots aquests aspectes fan aquesta obra difícil de traduir a altres llengües i gairebé incomprensible pel lector no-polonès. La primera part d'aquest article intentarà proporcionar algunes claus per a fer Trans-Atlantyk més accessible als lectors estrangers i que puguin arribar al nivell metafòric d'aquesta obra mestra de la literatura polonesa. Després ens concentrarem en l'anàlisi d'algunes traduccions i dels pròlegs introduïts per a guiar els lectors no-polonesos a través d'aquesta anti-epopeia nacional polonesa. A l'últim capítol considerarem Trans-Atlantyk a la llum de les idees de Milan Kundera sobre el destí dels grans artistes provinents de nacions petites exposades al seu assaig Les testaments trahis. Tanquem l'article amb algunes consideracions sobre el pes específic de Gombrowicz a les literatures nacionals polonesa i argentina i entre els millors escriptors de la Literatura universal.

PARAULES CLAU: Witold Gombrowicz, Trans-Atlantyk, Literatura polonesa, Literatura argentina, Milan Kundera.

\section{WITOLD GOMBROWICZ'S TRANS-ATLANTYK, A READING GUIDE FOR NON-POLISH READERS}

\section{ABSTRACT}

Witold Gombrowicz arrived to Buenos Aires on board of the Chrobry on august 22nd 1939. Some days later Nazi Germany invaded Poland and Gombrowicz decided to stay in Argentina, were he was to remain almost 24 years. In 1947, after almost 10 years hardly writing anything, he decides to explain his atypical arrival to the country and the weeks that followed. But that Trans-Atlantyk quickly took a new destination and brought the author back to his mother land, as it turned to a complex allegory on the relationship between individuals and the nation. To make it all more difficult, Gombrowicz chose a literary expression style coming from Sarmatian noblemen's memories' books from the $17^{\text {th }}$ century. Although the plot of the novel is set in Argentina, the main theme will be utterly Poland. All those aspects makes the novel difficult to translate to foreign languages and almost impossible to understand in a proper way to nonpolish readers. In our paper we'll try and give some keys to make this book more easily understandable to foreign readers, so that they can reach the metaphorical level of this polish 
major work. After that, we'll concentrate in some translation approaches used in different translations and the forewords incorporated to guide non-polish readers through this Polish national anti-epopee. In the last chapter we'll consider Trans-Atlantyk in the light of Milan Kundera's ideas on the destiny of great artists coming from small nations exposed in his essay Les testaments trahis. We'll finish with some considerations on the place achieved by Gombrowicz in Polish and Argentinean national literatures and amongst the best world authors.

KEY WORDS: Witold Gombrowicz, Trans-Atlantyk, Polish Literature, Argentinean Literature, Milan Kundera.

La menys coneguda de les meves novel-les, doncs aquestes trapelleries lingüístiques no són gens fàcils de traduir. Quin caram de bogeria va ser aquest Trans-Atlantyk! Des de qualsevol punt de vista! Quan penso que vaig escriure una cosa així, llençat a la costa americana, sense un ral, oblidat per tots. Però si en la meva posició calia escriure decididament una cosa fàcil de traduir i editar a altres llengües! $\mathrm{O}$, si és que havia d'escriure pels polonesos, doncs almenys que no ofengués els sentiments nacionals. I jo que em vaig atrevir a aquest cim de la irresponsabilitat, fabricant una novel.la inaccessible als estrangers a causa de les dificultats lingüístiques i provocadora per a l'emigració polonesa, l'únic medi amb l'ajuda del qual podia comptar (Gombrowicz 1996a: 105-106. Trad. del fragment: P. F.).

\section{INTRODUCCIÓ}

Hi ha un episodi arxifamós a la història de la literatura polonesa: a finals d'agost de l'any 1939 el jove escriptor polonès Witold Gombrowicz arriba a Buenos Aires a bord del vaixell Chrobry per a passar-hi unes setmanes invitat a la inauguració de la línia transoceànica Gdynia - Buenos Aires. Uns dies després Alemanya envaeix Polònia i Gombrowicz decideix quedar-se a l'Argentina, on passarà els següents 24 anys.

Precisament aquestes circumstàncies i aquesta Forma de la seva curiosa arribada a l'Argentina i dels seus primers anys d'exili són el que un bon dia de l'any 1947, tot passejant per un carrer de Buenos Aires i quan tot just feia un any que havia tornat a agafar la ploma, després de més de 6 anys d'inactivitat literària, recorda amb entusiasme i decideix posar-se a narrar. Tot i això, com ell mateix afirma, sense ni saber com, la futura novel-la se li gira cap a una temàtica nacional i li agafa una extraordinària volada que va molt més enllà de les pures memòries d'un exiliat i que donarà com a resultat un inesperat, estrany, dolorós, divertidíssim i preciós artefacte anomenat Trans-Atlantyk.

Tanmateix, fins a quin punt podem afirmar que Trans-Atlantyk, sens dubte l'obra més genuïnament polonesa de Witold Gombrowicz, és una "novel-la d'emigració"? Fins a quin punt no és el desplaçament només una circumstància, o millor dit, fins a quin punt és aquesta circumstància determinant en el desenvolupament de la magnànima empresa que representa Trans-Atlantyk?

Començarem fent un anàlisi general de l'obra, aportant algunes claus bàsiques que sovint passen desapercebudes als lectors no-polonesos. A més 
d'aclarir els temes principals que estructuren l'obra, donarem també una ullada a la manera com Gombrowicz presenta la colònia polonesa de Buenos Aires, que encara que finalment acabà essent un tema més aviat secundari, en principi havia de tenir un pes important en el primer Trans-Atlantyk, encara mental, de l'escriptor.

A continuació incloem un breu capítol sobre la llengua i el llenguatge emprats amb tant d'encert i conseqüència a Trans-Atlantyk.

Deixant de banda la importància que pugui tenir en el desenvolupament $\mathrm{i}$ en el missatge de la història contada, és evident que la condició d'emigrant, aquests més de $10.000 \mathrm{~km}$ que separen Polònia d'aquesta no-Polònia gombrowiczana anomenada Argentina, aillada i còmoda, juga un paper important per a l'autor a l'hora de què escriure i com escriure-ho, i a l'hora de fer-se un lloc a la literatura polonesa (d'emigració?). Aquesta situació col-loca també a l'escriptor davant d'una disjuntiva, on les noves possibilitats i les noves mancances s'alternen per igual, i on la postura adoptada serà determinant en la configuració de l'obra futura, encara que no forçosament de la seva temàtica.

Precisament aquest serà el tercer punt que tractarem en aquesta monografia. Perquè Gombrowicz, a l'Argentina estant, escriu el que escriu, però sobretot, per a qui ho escriu. Quines són les seves intencions i quines les seves raons al escriure una obra, com veiem en el llarg epitafi que obre el treball, tan poc adequada (tan insuportablement inadequada) per al moment personal de l'autor i històric de la nació a la qual va dirigida. En aquest sentit serà fonamental donar una ullada al destí de l'obra més paradigmàtica per a aquesta època de l'escriptor. On i com s'ha acollit Trans-Atlantyk. Quina ha estat la història particular d'aquesta novel-la. Per a la realització d'aquesta tercera part ens serà de gran ajuda una intermitent residència als Diaris (sobretot als dos primers volums), on la situació d'emigrant de l'autor és més palpable, tant en els temes tractats, com en el temperament de l'escriptor. A més dels Diaris, resulta també molt interessant donar una ullada a vàries de les poquíssimes traduccions de Trans-Atlantyk. Els diferents enfocaments $\mathrm{i}$ tècniques translatològiques dels traductors, així com els imprescindibles paratextos (o la seva absència) inclosos a les edicions no poloneses, resulten -com comprovarem més endavant- del tot reveladors.

I aquest tercer punt ens portarà a un quart, potser el més abstracte, que agafant com a punt de partida "Le mal-aimé de la famille" dels Testaments Trahis de Milan Kundera, intentarà definir la posició de Witold Gombrowicz en les volàtils nocions de Literatura universal i Literatura nacional. També ens resultarà interessantíssim en aquest punt contrastar les diferències que hi ha en l'apreciació de la figura i de l'obra (i també com s'estableix respectivament la jerarquia entre aquests dos termes) de l'escriptor que ens ocupa en les dues nacions $\mathrm{o}$, més concretament, literatures nacionals que se'l disputen: la polonesa i l'argentina. Per acabar, donarem una ullada al lloc que ocupa Gombrowicz entre d'altres escriptors polonesos al panteó de les lletres universals. 


\section{L'INTERIOR DEL TRANS-ATLANTYK}

Com va anar amb Trans-Atlantyk? Certa nit, tornant a peu de Caballito vaig començar a entretenir-me, ordenant els meus records sobre els primers dies de la meva estada a Buenos Aires, a la manera d'un Gran Guignol i alhora amb la força del mateix passat, em vaig sentir anacrònic, revestit per un estil antic, embolcallat en una certa esclerosis, gairebé prehistòric... i això em va fer sentir tan bé, que em vaig posar de cop a escriure una cosa que havien de ser les meves preprehistòriques memòries d'aquell temps. Que molesta aquesta fase preliminar, en la que cal treure d'un mateix la primera forma de l'obra, encara maldestre, no enriquida encara amb totes les petites inspiracions, amb les que només més tard va ensopegant la ploma. Només la perseverança permet obrir-se camí a través de la repugnant boira dels inicis. Però naturalment - i com sempre - només de posar-m'hi, l'obra se'm escapà, començà a escriure's sola: allò que havia plantejat com a crònica de les meves primeres activitats després d'arribar, es transformà en un obrir i tancar d'ulls, Déu sap com, potser durant aquests milers de concessions a la forma, en una estranya història sobre els polonesos, amb un "puto", un duel, fins i tot amb un kulig (petit carnaval en trineu de la noblesa polonesa, a la traducció castellana.: "la Gira") [...] Al cap d'un xic més d'un any em vaig adonar que era autor de Trans-Atlantyk. Però què caram era aquest Trans-Atlantyk? Una bogeria i una raresa trets del magí, teixits amb deu mil excitacions, una obra fantàstica. Polònia? Polònia se'm va ficar sota l'ala, esbojarrada ploma a pesar meu, només perquè escrivia sobre polonesos - i potser també perquè la sentia com a un anacronisme, i per consegüent em servia per al meu teatret, per a aquella decoració anticuada (Gombrowicz 1997a: 18-19. Trad. del fragment: P. F.).

"Però què caram era aquest Trans-Atlantyk?" Què és, doncs, Trans-Atlantyk? No és fàcil respondre a aquesta pregunta d'un forma unívoca. Comencem mirantnos una mica la novel-la per dins.

Com assenyala el mateix Gombrowicz en la cita anterior, Trans-Atlantyk neix amb la vocació de convertir-se en una espècie de llibre de memòries de la seva novel-lesca arribada i dels seus primers anys a l'Argentina, que foren evidentment els més durs. Gombrowicz creu que el material en si és prou apte per a escriure'n una novel·la. Com hem llegit, la idea el diverteix i l'encoratja. De l'any 1938 al 1947, amb algunes poques excepcions, no ha escrit res de ficció: una dotzena d'articles a la premsa argentina per a guanyar-se la vida, la traducció col-lectiva de Ferdydurke al castellà i poca cosa més. Ja a Polònia havia decidit passar una temporada sense escriure, doncs com afirma, "infantar aquell llibre (Ferdydurke) havia estat per a mi una commoció molt forta i sabia que havia de ploure molt abans no fos capaç de trobar i mobilitzar dintre meu materials nous" (Gombrowicz 1999: 212). Però quan esclata la guerra i es troba inesperadament a l'altre costat del món seran altres les raons que li impediran d'escriure. Sol, deprimit, sense un ral a les butxaques, vaga pels carrers de Buenos Aires. Sovint és presentat com a escriptor europeu a altres homes de lletres argentins, però de totes maneres allà ningú el coneix, ni a ell ni a la seva literatura. D'altra banda això al principi tampoc li importa massa (a més, al cap dels anys, quan comença a fer-se famós a Europa, aquest status d'anonimat perllongat al seu país d'adopció representarà per a ell un cert alleujament). 
Finalment, l'any 1947 decideix tornar a escriure i es posa a treballar en Ślub (El Casori). Quan l'any 1949 es posa a escriure Trans-Atlantyk, té una clara voluntat de posar en ordre tots aquells difícils primers anys. Desitja explicar-se. Que el mou a "desertar" i no tornar al país, quina és la seva vida a Buenos Aires i quins els seus estats d'ànim quan "allá degüellan, degüellan..." (Gombrowicz 1986: 24). No obstant, en aquest explicar-se no busca pas la comprensió i el perdó dels compatriotes, sinó posar ordre en el seu interior. Per exemple, la esmentada deserció apareix a Trans-Atlantyk com poc menys que un acte de covardia patriòtica, mentre que a la realitat fou del tot diferent (Gombrowicz quedà exempt de realitzar el servei militar, i per tant de tornar a Europa, per qüestions de salut). Aquest concepte de "traïció a la pàtria", que perpetra qualsevol individu massa "individualista" i poc compromès amb els afers nacionals, és genuïnament polonès, i potser per a altres nacionalitats pot semblar exagerat; però el cas és que Gombrowicz prefereix no quedar bé amb els compatriotes, no defensar-se de la falta de patriotisme, quan s'adona de la nova forma de gran epopeia nacional que va agafant el llibre. Tot el contrari, falsejarà la seva pròpia biografia (en un llibre pretesament de memòries!) per a així adoptar una postura intel-lectual més compromesa. Perquè, com indica Stefan Chwin, "res a Trans-Atlantyk és unívoc! Allò que és baix i desacredita el protagonista, per inesperats canvis de la faula mostra de repent el seu revers i es converteix en el més elevat" (Chwin 1996: 123). Però deixem les tesis de l'obra per a més endavant.

El que és realment important en aquesta primera fase embrionària de la creació és la troballa d'un mitjà d'expressió propi, originalíssim. Com llegim a la cita que obre el capítol, Trans-Atlantyk neix d'un divertiment en forma de records mentalment narrats en un estil èpic i antic, literari i camperol, genuïnament polonès: la gawęda. La troballa és tan interessant, que li dedicarem el següent capítol; de moment, només dir que és un llenguatge que li resultarà ideal per a la forma que ja des del principi vol donar a l'obra (i que resultarà encara incalculablement més profitosa per a la tesi que poc a poc es va formant a mida que Gombrowicz escriu Trans-Atlantyk).

Aquesta primera forma serà la d'unes memòries èpiques, com les que contaven els nobles campestres en el Barroc polonès. Es evident que ho passarà tot pel filtre del grotesc i li donarà així un to còmic que encisarà el lector, però el més important és que l'autor torna a Trans-Atlantyk a la metàfora com a mètode d'expressió que li permet ampliar el camp conceptual i crear una literatura més ambigua i irònica, tot i que lligada a la realitat. Potser afirmar que torna a la metàfora no sembli el més indicat, doncs tota la seva obra anterior i posterior de ficció està exclusivament formada per una successió interminable de metàfores encadenades. L'exemple més clar el trobem a Ferdydurke, novel·la d'idees (encara que surti de la sal de la terra), on absolutament cada element concret té el seu equivalent en un concepte o situació metaforitzades. Però si utilitzem el verb tornar és simplement perquè en un llibre de memòries en principi no és 
tan evident la utilització constant del símbol i la metàfora. A més, a TransAtlantyk hi trobem un parell de factors que converteixen aquest ús de la metàfora en una idea excepcional.

Per començar, el plantejament del subjecte literari. Gombrowicz deixa clar des del primer moment que està relatant les seves memòries: el llibre està escrit en primera persona i el protagonista principal correspon amb l'autor en nom, situació, professió... però estem parlant del mateix subjecte? Per una banda sí, Gombrowicz es disposa a narrar sense embuts la seva història personal; de totes maneres, aquestes "memòries", decideix narrar-les de forma metafòrica; és a dir, tot i que els episodis reals mai surten transcrits literalment a l'obra, una part considerable de les situacions i personatges ficticis tenen els seus equivalents en el que fou la vida personal de l'escriptor durant els primers anys 40. En aquest aspecte, a vegades són increïbles les semblances entre les situacions literàries que inventa Gombrowicz en altres de les seves obres i la manera com metaforitza les seves situacions viscudes en aquesta obra "autobiogràfica". Realment en pocs autors com en Gombrowicz s'esborra d'una forma tan gran la frontera entre ficció i realitat, entre vida i obra.

Tanmateix, el Witold protagonista de Trans-Atlantyk és molt més que l'autor de l'obra i poc a poc es va convertint en el subjecte literari que portarà el fil conductor d'unes tesis de gran volada intel·lectual que superaran en molt el terreny del purament memorialístic. Doncs, com indica l'autor en nombroses ocasions, Trans-Atlantyk és més d'un llibre i entre d'altres coses és també una novel-la de tesis. De fet, aquesta ha estat sempre la lectura principal de la novel-la i també la que va defensar l'autor al principi. Però tot i ser una novel·la carregada d'intencions de caire superior, tot i ser "una nave corsaria que contrabandea una fuerte carga de dinamita, con la intención de hacer saltar por el aire los sentimientos nacionales(...) y superar la "polonidad'" (Gombrowicz 1986: 8), sempre podem llegir Trans-Atlantyk també com a llibre de memòries o, millor dit, com apunta Vincent Colonna, com un dels primers exercicis d'autoficció de la literatura moderna (Colonna 2004: 12). Les nombroses metàfores que sovint brillen d'ambigüitat, amaguen en la majoria dels casos episodis viscuts. Per exemple, Constantin Jeleński no dubta en assenyalar la correlació directa entre el "gran escriptor" que apareix a la vetllada literària del principi del llibre amb Jorge Luis Borges, que l'humilia a la vetllada i que sempre l'ignorà a la vida real (veure: Gombrowicz 1991), tot i que Ricardo Piglia hi veu més aviat a Eduardo Mallea (capitost literari dels anys $40 \mathrm{amb}$ qui Gombrowicz es va trobar més d'una vegada) (Piglia 1986). La situació sencera pot recordar també el famós sopar a casa dels Bioy Casares-Ocampo (ambdues s'acaben amb una passejada pel Retiro...) Aquí la correlació és clara, però la grandesa de TransAtlantyk és que la vetllada no reflexa tan sols la trobada dels dos genials escriptors, sinó l'essència de moltes situacions semblants que, com sabem pels Diaris i per nombrosos documents, realment tingueren lloc. Fixem-nos que la història narrada a Trans-Atlantyk transcorre al llarg d'aproximadament un mes, 
mentre que concentra les vivències de més de quatre anys, els anys de la guerra. Aquesta és sens dubte una de les grans originalitats de l'obra, doncs, si bé emmascarar personatges o situacions personals en el món de la ficció ha estat una pràctica recurrent entre molts escriptors, el fet de fer-ho conservant el nom i encara més el fet d'escriure unes memòries no dels fets concrets sinó d'una certa atmosfera és del tot nou. I més si tenim en compte que quan li convé l'autor falsifica les pròpies memòries, sempre i quan es conservi l'essència d'aquestes. Gombrowicz és en aquest sentit un autor que ho subordina tot a la gran literatura, a la força d'una història narrada. Així, el lector sovint es perd en tanta metàfora i sent el terra fonedís sota els peus ja que, en certa manera, TransAtlantyk és una guia per a uns anys de Gombrowicz, però per sobre de tot és una novel-la que, com a tal, dona cabuda a molts elements de diferent índole. L'autor adverteix: “...en definitiva (Trans-Atlantyk), no es otra cosa sino yo mismo, mi 'vibración', mi desahogo, mi existencia”' (Gombrowicz 1986: 9).

Un dels aspectes memorialístics clau per a entendre aquesta novel-la és la descripció que s’hi fa de la comunitat polonesa de Buenos Aires. També aquí buscaríem en va els personatges del llibre a la realitat de l'època. No obstant, aquests no són, com res en aquesta novel·la, fruit de la pura ficció i en veritat ens expliquen moltes coses d'aquesta comunitat. Tot contant les seves memòries, Gombrowicz desitja passar comptes amb una sèrie de personatges $\mathrm{i}$ situacions. Tot i que al pròleg de la primera edició polonesa al país, fart de les crítiques que li arribaven a cabassos d'entre l'emigració polonesa que ja havia llegit l'edició parisenca d'Instytut Literacki, inclou unes línies declarant que "Transatlàntico es una fantasía. Todo ha sido inventado y sus vínculos con la Argentina verdadera son muy leves, así como con la colonia polaca de Buenos Aires" (Gombrowicz 1986: 10), la seva intenció era que la comunitat polonesa de la capital argentina i les seves trifulgues quedessin ben retratades a la novel-la. Les seves males relacions amb els compatriotes d'allà eren evidents; Gombrowicz mai deixava que es barregessin els seus coneguts poloneses amb els seus amics argentins. En una carta a Józef Wittlin, que es trobava a Nova York, Gombrowicz li demana suport econòmic i es queixa que "la colònia polonesa d'aquí és una monstruosa banda de cretins i un ramat de porcs repugnants (a part de comptades excepcions) i a més, no sé ben bé per quina raó, aquests animals han començat a odiar-me i ara em fan la vida impossible." (Gombrowicz 1996b: 123. Trad. del fragment: P. F.) Realment, no es pot negar que aquesta comunitat polonesa, vista des de la perspectiva de l'escriptor, surt reflectida a Trans-Atlantyk en primer pla. Per començar, la indefinició del parent-o-conegut Cieciszowski, llavors de forma més explícita el curiós trio del Baró, Pyckal i Ciumkala amb els seus embolics, les enveges, els rancors, “...el vell molí, ...un panet mossegat fa anys,..." (Gombrowicz 1996c: 25. Trad. del fragment: P. F.), però també amb la seva mútua necessitat i inseparabilitat. En la personalitat tan diferent d'aquests tres grotescos personatges sembla també endevinar-s'hi tres models estereotípics del polonès emigrant i qui sap si també 
en certa manera del polonès standard. Tres maneres diferents, i les tres reprovables, de ser polonès, diguem-ne, a l'antiga. En tot cas el que sembla un tret més genuïnament característic de l'emigració polonesa és la seva curiosa relació de dependència/rancor. Com hem dit més amunt, segurament també aquí es repeteix alguna situació especialment característica (dolorosa?) en la vida real de l'escriptor, encara que convenientment disfressada per l'enjogassat Gombrowicz. La legació consular, amb l'ambaixador, el conseller Podsrocki i companyia, representen encara un altre model d'emigració polonesa (i com veurem més endavant, no tan sols d'emigració) amb el que es topà Witold. L'alta jerarquia de la comunitat polonesa a l'Argentina es veu constantment obligada (però, per qui?) a deixar el pavelló alt, constantment ha de mostrar que allò polonès sempre és millor. En aquest sentit, la legació només representa una branca o un aspecte d'un fenomen polonès i d'altres nacions perifèriques molt més ampli, que apareix personificat en el llibre també per la pròpia legació: el complex d'inferioritat de les nacions petites. Aquest aspecte no és altre que la missió que senten els polonesos a l'emigració d'exaltar tot allò que és nacional; l'obligació de comprometre's encara més amb la nació en perill pel fet d'estar en contacte amb els estrangers. Però com esclareix al Testament, amb qui realment passa comptes al burlar-se del comportament ridículament nacionalista de la legació i altres personatges del bàndol polonès és amb els escriptors i gent de cultura polonesos a l'emigració que propugnen el mateix model. Especialment amb ells, com a responsables intel-lectuals de la resta, que no tan sols no abandonen, sinó que intensifiquen un model que en aquells moments definitivament fa mal a la imatge del país a l'estranger (“...pero sus palabras eran vacías, todo vacío..." Gombrowicz 1986: 121). Segons Gombrowicz, després de la terrible pallissa que ha rebut i continua rebent Polònia, resulta, si no risible, directament humiliant que una sèrie de poetes exiliats segueixin declamant les glòries(?) de la immortal(?) Polònia. Gombrowicz explica a Dominique de Roux que se sentia tan indignat com a escriptor (ja que aquells escriptors malbarataven una llibertat d'expressió que en aquells anys els era exclusiva) $i$ fins i tot com a polonès (aquests mestretites donaven una imatge del país a l'estranger humiliant de tan falsa, hipòcrita i a més pretensiosa) que decidí prendre cartes en l'assumpte i acabar amb ells i amb aquest model de polonitat d'una vegada per totes. Però si ho feu, l'acció no podia limitar-se a un atac entre intel-lectuals, Trans-Atlantyk havia de buscar les últimes conseqüències, el canvi total.

Aquí trobem ja un dels temes que amoïnen l'autor polonès a TransAtlantyk i bàsicament al llarg de la seva obra (Diaris, El Casori, Ferdydurke...) i que el refermen també com a gran filòsof: la incapacitat de superar la immaduresa, aquesta vegada aplicat a les petites nacions i molt especialment a Polònia. Aquest complex d'inferioritat de la perifèria respecte a París que desemboca en una forçada recerca de la superioritat representarà un dels temes clau del llibre, que acaba convertint-se en una radiografia nacional amb 
programa inclòs. D'altra banda aquest complex d'inferioritat política, econòmica i social de les nacions pobres i constantment amenaçades és també extrapolable a les cultures (i molt concretament a les literatures) nacionals d'aquests països, com Gombrowicz comenta molt especialment als Diaris, però també a Trans-Atlantyk.

Pels Diaris sabem que de bon principi no era la intenció de Gombrowicz crear una obra tan polititzada o patriòtica com acabà essent Trans-Atlantyk. El més probable és que comencés a divertir-se escrivint els diàlegs del ministre i el conseller i s'adonés que d'aquell simple divertiment en podia sortir una crítica molt més elevada, que d'altra banda portava dintre des de feia molts anys. Així doncs, es llançarà definitivament a una dolorosa (divertidíssima), però necessària polèmica sobre el patriotisme, les exigències de la nació envers l'individu i, finalment, la voluntat de l'individu envers la nació. Aquí Gombrowicz troba la raó de ser d'una de les seves novel-les més ambicioses i perfectes (a pesar d'haver estat escrita en gran mesura en un despatx compartit del Banco Polaco de Buenos Aires). A partir d'ara, cada un dels personatges i les situacions encarnaran alguna idea, corrent o situació relacionades amb el nacionalisme polonès i la seva història. Així doncs, paral-lela a la història narrada, les aventures de Gombrowicz a l'Argentina, podrem anar llegint entre línies una altra història on els protagonistes seran la pàtria i el que serà possiblement el seu rival més temible: l'individu, el subjecte polonès com a individu. Com alliberar aquest individu de les urpes de la pàtria: sembla clar que aquest és el tema central de la novel-la. Com més avança la història, més avança només en relació a aquesta línia argumental al-legòrica i el final de Trans-Atlantyk no té massa sentit sense tots aquests conceptes metaforitzats, mentre que respecte a ells, és un grand finale absolutament rodó.

Afirmar tot això és com dir que el lector no-polonès no està en condicions d'entendre de la missa la meitat. Aquesta discussió vindrà a la segona part d'aquest treball, però en tot cas, per a fer més intel-ligibles aquests aspectes del llibre a un públic estranger, resulta imprescindible aclarir alguns fets i conceptes bàsics de la cultura i la història poloneses.

El primer referent que cal tenir en compte, relacionat tant amb el nacionalisme històric polonès tractat a Trans-Atlantyk com amb el llenguatge arcaïtzant emprat en l'obra, és el del Sarmatisme. Aquest corrent ideològic imperant a la noblesa terratinent polonesa els segles XVII i XVIII propugnava l'origen sàrmata (una antiga tribu nòmada d'origen irànic que es va passejar per les planes d'Europa Oriental del s. V a. C. al IV d. C.) dels nobles polonesos, fet que pretesament els imbuïa d'una valentia, un sentit de l'honor i en general una sèrie de virtuts de les que manquen les altres nacions. A mida que la corona polonesa va anar perdent poder econòmic i polític, la supèrbia i la fatxenderia del Sarmatisme no va fer sinó augmentar (clar símptoma del creixent complex d'inferioritat). El noble sàrmata avorreix la política, menysprea tot allò que no és polonès, s'interessa només per la caça i la bona vida de palau. D'altra banda 
les guerres constants contra musulmans, ortodoxes i protestants aniran cimentant una identificació cada cop més estricte entre el ser polonès i la fe catòlica: a partir de mitjans s. XVII Polònia es veu a si mateixa com a "Baluart de la Cristianitat". Però si bé l'estúpida mentalitat sàrmata perviurà parcialment en la mentalitat d'alguns polonesos, serà el Romanticisme i la tradició de les insurreccions armades contra Rússia el que donarà la fesomia definitiva, després del repartiment de Polònia, al nacionalisme polonès i en algun aspecte també al caràcter nacional. El Romanticisme polonès explota el paper de víctima de la nació polonesa tot destacant-ne, però, l'honor, la valentia, l'espiritualitat. Polònia es bolcarà cap al catolicisme i naixerà el concepte de Polònia com a "Crist de les nacions". Aquests dos moviments ideològics configuraran fèrriament la dicotomia Déu/Pàtria, polonitat/catolicisme. Tota aquesta sèrie de conceptes creats pel Sarmatisme i reforçats pel Romanticisme de cara a fer-se la víctima davant d'Europa i aixecar els ànims a la pàtria tornaran a la cultura polonesa sempre que la situació històrica ho requereixi (durant el positivisme en la figura del Nobel Sienkiewicz, les patriòtiques novel-les del qual es llegien fervorosament al principi del segle XX i s'adapten com xurros a la gran pantalla als anys $90 \ldots)$

Concentrem-nos ara en la figura de l'impulsor i un dels màxims creadors del sentiment patriòtic polonès i en la seva obra clau, amb qui Gombrowicz mesurarà les seves forces a Trans-Atlantyk. Aquests no són altres que Adam Mickiewicz i la seva obra Pan Tadeusz, que funciona a Polònia com una espècie d'epopeia nacional. Abans que res, cal indicar que tot i no ser excessivament conegut arreu d'Europa, Mickiewicz representa a Polònia una figura monumental que no passa mai de moda, admirada en general per tothom com el més gran (o almenys un dels millors) poetes polonesos de tots els temps.

Quan el 1831 fracassa l'Aixecament de Novembre, Mickiewicz es troba a Roma; a pesar de que la majoria de les seves obres són de caire patriòtic i estan destinades a aixecar els malaurats sentiments nacionals, Mickiewicz no s'enrola a l'exèrcit, conscient que el seu destí és ajudar la pàtria amb la ploma. Quan a França escriu Pan Tadeusz és plenament conscient d'estar escrivent el que serà l'epopeia nacional. En aquesta obra necessària, previsiblement maniqueista, hi hauran de sortir els bons patriotes, els traïdors a la pàtria, que coquetegen amb els russos, les divagacions del protagonista i, evidentment, la victòria de l'honor i la valentia dels polonesos. Però encara un element imprescindible: el gran ball que tanca l'obra ha de representar l'ineluctable reconciliació nacional.

Segur que a aquest punt el lector atent ja s'adona de la sèrie de semblances (i diferències) que hi ha entre els dos escriptors polonesos i les seves obres "més patriòtiques". A més de totes les circumstàncies que esmentarem a continuació, ens sembla també revelador el status dels dos autors i la respectiva consciència, tant de la pròpia genialitat, com del seu compromís històric. Ja que, sí, també Gombrowicz aspira a convertir-se en una mena de reformador del seu poble i... d'escriptor nacional (veure: Jarzębski 1981). Mentre Mickiewicz és considerat el 
poeta nacional polonès, admirat i estimat avui dia encara per tothom, inclosos escriptors i acadèmics, Gombrowicz és probablement l'escriptor polonès més conegut i respectat a l'estranger, el més internacional dels autors polonesos.

Però tornem a l'Argentina. Mentre escriu Trans-Atlantyk i ja ha tret a relluir el patetisme de certs comportaments patriòtics, Gombrowicz s'adona de les nombroses semblances entre la seva situació (i la del país) i la de Mickiewicz uns cent anys abans. Sap que si vol aspirar al lloc més alt del panteó de la literatura polonesa tard o d'hora haurà de mesurar les seves forces amb el poeta romàntic, al qual, no ho dubtem, a pesar de tot, Gombrowicz respecta i admira. Al seu assaig "Gombrowicz i Forma polska", Stefan Chwin aclareix:

Perquè escrivent la seva novel-la Gombrowicz necessitava (i volia!) enfrontar-se amb Mickiewicz. En primer lloc amb el Mickiewicz creador de les idees bàsiques i de l'imaginari que des de fa lustres defineixen el sentiment dels polonesos, en segon lloc amb Mickiewicz com a - sí! - contrincant... del mateix Gombrowicz en la lluita pels llocs més alts de la literatura polonesa (Chwin 1996: 127).

Per això converteix el seu Trans-Atlantyk en un claríssim anti-Pan Tadeusz. Aprofitant els personatges que ja té i introduint-ne de nous, Gombrowicz va creant una història paral-lela a Pan Tadeusz (i a les seves pròpies memòries porteñas, no ho oblidem) però de signe invers. Si Pan Tadeusz sotmet l'individu a la pàtria, Trans-Atlantyk el sotmetrà a la filistria, és a dir, a la pròpia individualitat. Però Gombrowicz no vol pas escriure una simple novel.la de tesis com ho fera Mickiewicz; l'autor de Ferdydurke es mou amb més comoditat en el terreny de l'ambigüitat i defuig els programes simplistes. Així que per a Trans-Atlantyk torna a un subjecte neutre, que es deixa influir per les circumstàncies que l'envolten; un personatge semblant al protagonista de Ferdydurke, un home sense atributs deformat per la Forma de la seva vida, que es veu novament involucrat en una història que al principi li és aliena, però que més endavant s'adona que afecta a tothom i que per tant no pot defugir. Però si a Ferdydurke l'imperatiu de la Forma ve donat per l'educació, els lligams i l'estratificació socials, a Trans-Atlantyk qui marca el destí dels individus és la pàtria. A Witold la deformació l'afecta per partida doble, com a individu i com a escriptor.

Gombrowicz no deixa mai que aquesta història perdi la seva simetria, encara que resulti evident de quin bàndol està l'autor. Per a dissimular aquest bàndol Gombrowicz es veu obligat a radicalitzar fins a les últimes conseqüències cada postura, cosa que encaixa perfectament amb l'estil per naturalesa grotesc de l'autor. Per a simbolitzar el patriotisme polonès d'arrel mickiewiczana i ridiculitzar alhora els patètics efectes del complex d'inferioritat nacional, Gombrowicz es val dels ridículs personatges de la legació; per a personificar la pàtria (una pàtria que és la Polònia subjugada pel nazisme i no cap altra) i les seves exigències sobre el "fills", s'inventa la figura del pare, Tomasz, que pretén enviar el seu fill a la guerra i a una mort segura. Tot això 
resulta evident, però per a mostrar les aspiracions de l'individu ha de buscar una postura radical, que compliqui les coses fins i tot al lector més progressista: és així com apareix la figura de Gonzalo, el puto. Aquest carismàtic personatge no tan sols busca l'alliberació del fill de les urpes del pare; en un altre pla més universal representa l'alliberació total de l'individu, fins a les capes més profundes de la psicologia humana, per això apareix sota la forma d'un pervers depravat sexual. Com molt encertadament assenyala Jeleński, Gonzalo no és res més que un altre alter-ego del propi Gombrowicz (almenys d'un cert Gombrowicz, aquell amant de la joventut i de la immaduresa, aquell que es passeja per les nits per l'estació del Retiro...), ja que el puto fa allò que Witold no gosa fer. Jeleński assenyala al pròleg de l'edició francesa:

\footnotetext{
Ce apparentment ce puto, le richissime Gonzalo, 'métis né en Lybie, père portugais, mère persano-turque', qui souffle à Gombrowicz l'idée de remplacer la patrie de l'ordre et de la tradition par la 'Filistrie' de subversion et du devenir. Or, si Gombrowicz se réserve le rôle du narrateur dans tous ses romans, il délègue toujours à un double, à un autre luimême, le rôle du metteur en scène chargé de monter la machine infernale qui en est le véritable enjeu. Ce double, dans Trans-Atlantique, c'est de toute evidénce Gonzalo, dont Gombrowicz écrit: ' '...ce marcheur qui parallèle à moi marchait et marcheit...lui et moi en un ètrange couple à jamais appariés'. Le double s'appelle en allemand Doppelgänger celui qui marche à côté, qui double la marche de quelqu'un (Jeleński 1976: 10-11).
}

S'ha parlat molt de les tendències homosexuals de l'autor i les referències d'aquest tipus a Trans-Atlantyk podrien perfectament donar peu a diverses suspicàcies. Però més enllà del que hi pugui haver de vivencial, el que resulta evident és que a Trans-Atlantyk l'homosexualitat de Gonzalo i les enveges al respecte del protagonista són, abans que res, símbol de llibertat.

Quant al paper d'Ignacy, el fill, no cal dir que representa al polonès de carrer entorn al qual gira tota la bagatel-la. El personatge conductor de Witold juga un rol semblant al d'Ignacy, encara que Witold poc a poc va agafant consciència de la situació; representa per tant l'intel·lectual o l'escriptor polonès, i tota l'obra és també una llarga divagació sobre el paper de l'home de lletres, polonès concretament, centreeuropeu aproximativament, universal en general, quant a la postura a prendre en relació a les exigències de la nació en moments difícils, la llibertat de l'escriptor en una cultura perifèrica, el seu complex d'immaduresa, etc, etc.

Però els elements esmentats són només les guies mestres de l'estructura simètrica de Trans-Atlantyk. Tanmateix trobem un sèrie d'elements en clau que enriqueixen el marc d'aquesta crítica nacional. Agafem l'exemple del Club dels cavallers de l'esperó. Podem afirmar que no és necessària cap clau, doncs l'escena mostra la ridiculesa d'alguns comportaments psicològics genialment desemmascarats, però si agafem l'escena dintre l'àmbit general de l'epopeia sobre els valors nacionals, el club amb el contable al capdavant agafen un caire absolutament diferent. El lector polonès avisat pot descobrir en el club, per 
exemple, la llarga història de conspiracions de la Resistència polonesa (en polonès resistència es diu podziemie, és a dir, "subterrani" o "soterrani", precisament on es troba ubicada la seu del club), com apunta Jarzębski; o també, segons Chwin, la branca més ultra-catòlica i radical del nacionalisme polonès vuitcentista anomenat Messianisme, que partint del lema "Polònia, Crist de les nacions", propugnava la purificació pel dolor i obligava a l'amargor de l'individu per la pèrdua de la nació. Es més, Chwin senyala fins i tot les increibles semblances del contable i el seu club amb Julian Towiański, principal ideòleg del Messianisme, i la seva macabra secta, establerta a París, que obligava sovint a pràctiques masoquistes als seus membres.

I la llista de semblances no s'acaba aquí; en l'estrany palau de Gonzalo podem veure-hi la fastuosa mansió de l'extravagant comte lituà Bogusław Radziwiłł, considerat com a traïdor a la pàtria, només per a mencionar un altre exemple d'un llarg etcètera de ressonàncies i equivalents.

Així doncs, Trans-Atlantyk, a més d'una novel-la de tesis i una crítica ferotge als hàbits de la vella Polònia, és també una increïble parodia plena de sorpreses per al lector avisat (encara que malauradament només pel polonès, i encara culte). En aquest sentit, el final de l'obra és altament significatiu. Com ja hem assenyalat anteriorment, hi ha un paral-lelisme claríssim entre el ball final de Pan Tadeusz i el de Trans-Atlantyk. Mentre que Mickiewicz representa amb la solemne ballada del polonez la reconciliació nacional, Gombrowicz, en una burla tan subtil com sonada, tancarà Trans-Atlantyk amb la viva dansa de la mazurka $\mathrm{i}$ la cracoviana que només condueixen al famós "bumbum" i "bambam" i tot s'acabarà en una estrepitosa riallada. Es a dir, riallada a Mickiewicz, riallada als mals hàbits del nacionalisme polonès, riallada al destí de l'escriptor... però no parricidi, ni molt menys filicidi, sinó per sobre de tot un meravellós final obert que dona la paraula al lector.

Com veiem, Trans-Atlantyk és una obra tan rica i ambigua que de ben segur pot oferir tants significats ocults, interpretacions i formes de lectura com lectors tingui. Aquest breu anàlisis només ha pretès aportar algunes de les claus més clares de l'obra (en general confirmades per l'autor), especialment aquelles que es fan més difícils de copsar al lector estranger.

\section{UNA XERRAMECA DE NOBLES COM A DISCURS MODERNITZADOR}

El petit capítol que segueix a continuació segurament sobraria si aquesta monografia estigués escrita en polonès, però per a algú que coneix l'obra des de la traducció castellana i no parla polonès em sembla imprescindible comentar una mica la curiosa i rica barreja lingüística en que està escrit Trans-Atlantyk.

Com podem llegir a l'epitafi que obre la primera part, ja des dels primers instants de gestació de l'obra, aquella nit tornant de Caballito, Gombrowicz imagina les seves memòries en un estil èpic $i$ antic, tot buscant un to adequat a la seva gesta. De seguida l'autor se sent seduït per la gawęda com a base 
lingüística de la seva obra. La gawęda és un llenguatge o estil particular creat pels nobles polonesos a l'època del Barroc per a explicar a altres nobles les seves aventures en les incomptables guerres en les que es veié involucrada la Confederació poloneso-lituana durant el segle XVII. El seu màxim exponent fou Jan Chryzostom Pasek, les Memòries del qual Gombrowicz emularà a TransAtlantyk. La gawęda era un estil xabacà, entre grandiloqüent i vulgar, barreja de llengua culta i pagesa, plena de llatinismes i de proverbis, típica de la noblesa rural. Era també un estil eminentment oral, cosa que s'adiu amb l'estil harmònic i musical de la frase gombrowiczana. Des dels seus inicis a meitats del segle XVII, la gawęda anirà evolucionant en diferents direccions gràcies a alguns escriptors que la reprenen, com per exemple Henryk Rzewuski durant el romanticisme. A finals del s. XIX, Henryk Sienkiewicz reinventa aquest llenguatge ja mig oblidat per a construir els diàlegs dels herois de les seves novelles històrico-patriòtiques (Ogniem i meczem, Potop, Pan Wołodyjowski...), tot adaptant-lo una mica al polonès de l'època. Com és sabut, les obres de l'autor de Quo vadis es convertien ràpidament en best-sellers que arribaven a totes les capes de la població. En aquest sentit Gombrowicz comptava amb un as a la màniga. Podia valdre's d'aquell polonès antic i extravagant, molt adequat per a la novel-la que volia escriure, tot passant-lo en certa manera pel filtre de Rzewuski i Sienkiewicz. Així, el llenguatge resultava exòtic, però alhora comprensible. De totes maneres la gawęda no constitueix per a Gombrowicz més que la base d'un projecte lingüístic de més abast. Al parlar provincià i fatxenda del Pamiętnik (Memòries) de Pasek i a l'exaltació del positivisme patriòtic de Sienkiewicz hi afegeix l'apassionament romàntico-messiànic de Mickiewicz i ho condimenta tot amb una abundant fraseologia de caire popular. Així que tot sol a l'Argentina, Gombrowicz crea un llenguatge pagès i culte, popular i exòtic alhora, amb una àmplia barreja de registres, de ressonàncies sàrmates $i$ messiànico-patriòtiques per a... expressar conceptes filosòfics amb la fi de fer saltar pels aires el vell model de polonitat.

Aquest estil, per ser immanent a la tradició polonesa i per extensió també a un model concret de comportament, activa la memòria comuna i l'horitzó cognitiu del lector polonès, convertint-se en una part inseparable del nivell semàntic de l'obra. Però atenció: l'ús que Gombrowicz fa a Trans-Atlantyk d'aquesta gawęda condimentada al seu gust no és només irònic. Per a Gombrowicz, autor que no repudià mai cap part del llenguatge per considerarla malsonant o poc elevada, la gawę̧da sàrmata és un medi d'expressió ideal per al gènere de memòries i aventures, deixant de banda les connotacions que aquest estil arrossegui. No obstant, després de Trans-Atlantyk, ja ningú podrà rescatar l'antiga gawęda del seu orgull ferit. Com un Don Quixot de la modernitat, Gombrowicz sacrifica la gawęda i tot el Sarmatisme en el seu propi altar, tot creant-ne amb les seves restes el més preciós monument, tal com fera Cervantes al s. XVI amb les novel-les de cavalleries. El sorprenent invent de Gombrowicz 
el converteix, en l'aspecte formal (a més del programàtic, està clar) en una espècie de profeta de la literatura polonesa.

A més, cal no oblidar que Gombrowicz superposa a aquesta base lingüística arcaïtzant el seu personalíssim estil. El seu ritme accelerat i cridaner, però musical i harmònic alhora, s'adiuen perfectament amb el caràcter oral de la "xerrameca noble" o gawęda (d'aquí vénen les paraules en majúscula enmig de la frase, que marquen els èmfasis que ha de tenir la narració oral). Així mateix succeeix amb l'al-literació, tan gombrowiczana i tan important a Trans-Atlantyk. La metàfora i el símbol es troben com peix a l'aigua en aquest marasme superlativament grotesc.

Evidentment la decisió d'usar un llenguatge d'aquestes característiques (sumat al fet de tocar un tema d'aquestes característiques!) condemnava TransAtlantyk a la pràctica exclusivitat del públic lector polonès. Al cap dels anys Gombrowicz es lamentava que la gent no conegués Trans-Atlantyk. Efectivament, quan gran part de la seva obra es trobava ja traduïda a multitud de llengües i agrupada en "biblioteques Gombrowicz", Trans-Atlantyk restava desconeguda al lector no-polonès. Gombrowicz només arribà a conèixer en vida la traducció de l'obra a l'alemany. Posteriorment apareixeran la versió castellana (1969), la francesa (1976), l'anglesa (tan sols el 1994) i algunes més ja al tercer mil·leni, "doncs aquestes trapelleries lingüístiques no son gens fàcils de traduir" (Gombrowicz 1996a: 105-106), en paraules de l'autor.

La versió alemanya peca d'excessiva literalitat i és en conseqüència poc natural en la llengua d'arribada; la francesa de Constantin Jeleński i Geneviève Serreau no respecta l'estil original, però almenys introdueix algun o altre element arcaïtzant; l'espanyola de Sergio Pitol i Kazimierz Piekarek ignora completament l'arcaisme de l'original (a més, no inclou ni un sol para-text, en una obra tan connotada), en una traducció "comercial", però que almenys funciona en la llengua d'arribada; la traducció anglesa és la més ambiciosa i atrevida, escrita en un anglès del s. XVII que, no obstant, sense un pont a l'estil de Sienkiewicz, resulta massa allunyat de l'anglès modern $i$ es torna incomprensible pel lector mitjà, $i$ això sense tenir en compte que les connotacions implícites en aquest anglès arcaic no són les mateixes que les que comporta el popular parlar dels herois sàrmates de Sienkiewicz. Com veiem, un panorama força desolador per a la recepció internacional d'una peça única en la història de la literatura universal...

En aquest punt, cal plantejar-nos per què i per qui escrigué Trans-Atlantyk l'autor polonès? Era Gombrowicz l'artista pur que no es preocupa per cap circumstància exterior al seu art? Potser en certa manera sí, però Gombrowicz era també un autor que aspirava al més elevat, que promocionava les seves obres i que no escrivia per al calaix.

Llavors, per què escriu una obra que sap positivament que difícilment podrà ser traduïda a cap llengua ni entesa per cap estranger? No pot suavitzar 
el seu estil, la seva forma i continguts i tornar-los ni que sigui una mica més adaptables?

El més segur és que quan Gombrowicz emprengué l'empresa d'escriure Trans-Atlantyk no es plantegés aquests aspectes. Senzillament havia trobat en la gawęda una forma d'expressió tan genial per a les idees que volia tractar que no la va poder deixar passar. De totes maneres, en el següent capítol intentarem indagar més sobre les intencions i les esperances de l'escriptor polonès al escriure aquesta polèmica obra.

\section{UN LECTOR IMPLICIT A MÉS DE 10.000 KM}

El juicio que me interesa mantener es el de quienes consideran el libro como "un ajuste de cuentas con la conciencia nacional" y no "una crítica de nuestros defectos nacionales" [...] No lo niego: Transatlántico es, entre otras cosas, también una sátira, y también un intenso ajuste de cuentas..., no con una Polonia en particular, entendámonos, sino con aquella Polonia creada por las condiciones de su existencia histórica y por su dislocación en el mundo (o sea con la Polonia débil). Convengo también que Transatlántico es una nave corsaria que contrabandea una fuerte carga de dinamita, con la intención de hacer saltar por el aire los sentimientos nacionales, hasta hace poco vigentes entre nosotros. Es más, eso oculta en su interior una explícita propuesta que tiene que ver con aquel sentimiento: "superar la polonidad" [...] No, Transatlántico no contiene ningún tema, fuera de la historia que allí se narra. [...] Debería salvar ahora otro peligro: y es que esta obra no sea leída con una visión demasiado estrecha y superficial. [...] En vistas de su publicación en Polonia debo exigir una lectura más profunda y universal (Gombrowicz 1986: 7-9).

Quan vaig començar Trans-Atlantyk no tenia cap indici que el llibre em conduiria a Polònia..., Covardia! Falta de patriotisme! Quina cosa tan estranya! Trans-Atlantyk és l'obra més patriòtica i més valenta que he escrit mai (Gombrowicz 1999: 135, 171).

Tot el que escric és únicament bàsic i universal. Encara que volgués no podria reduir la meva temàtica, que serà sempre l'home i el món. Però Trans-Atlantyk afecta també Polònia, i aquesta simple paraula, "Polònia" és suficient per a despertar en ells tots els complexos locals. [...] aquesta obra no és res més que jo mateix. No es una sàtira. No passo comptes amb la consciència nacional. No és filosofia. No és historiosofia. Què és doncs? Es una narració, que un dia vaig narrar. En la qual entre d'altres hi apareix Polònia. Però no és Polònia el tema; el tema, com sempre, soc jo i només jo, son les meves aventures, no les de Polònia. Només que jo soc polonès (Gombrowicz 1997a: 13, 29).

Per a qui escriu, doncs, a l'Argentina, Witold Gombrowicz? Cap a on es dirigeix aquest Trans-Atlantyk? La resposta a aquestes preguntes sembla clara: el lector ideal de Trans-Atlantyk era (és) un lector polonès culte. Tanmateix, Gombrowicz recalca sovint que les seves obres només contenen temes universals; és més, reclama per a Trans-Atlantyk una lectura més "amplia i universal". En tot cas, segurament el més interessant que podem fer dels sovint enganyosos comentaris de la pròpia obra és plantejar-nos si hi ha una contradicció o una evidència en buscar una lectura universal d'una obra tan local. Aquest és un dels punts que intentarem desentrellar en aquest capítol. 
Per començar, donem una ullada a la recepció polonesa de la novel·la. Trans-Atlantyk apareix publicat per primera vegada a París l'any 1951 en forma de fulletó a la revista Kultura, portaveu cultural de l'emigració polonesa a França. El 1953 sortirà en forma de llibre (juntament amb Ślub, El casori), editat per Instytut Literacki també a París. Ja des del principi originarà una gran polèmica entre els primers lectors de l'emigració polonesa. Gombrowicz assegura als Diaris que no s'esperava un revolt tan gran quan el 1950 acabà d'escriure Trans-Atlantyk. Siguin sinceres o no les seves afirmacions, el cert és que podia esperar-se una allau de crítiques encara que, com veurem, aquestes agafaren les formes més sorprenents i inesperades. Està clar que en aquest primer moment resultà per a la majoria una novel-la indignant. Jerzy Giedroyc, director i editor de Kultura i Instytut Literacki, afirmava que la revista va perdre més subscriptors després de publicar Trans-Atlantyk, que no per la publicació dels articles polítics més controvertits. Però mirem-nos més detalladament les diferents cares d'aquesta indignació i confrontem-les amb el que s'esperava l'autor.

La crítica més habitual fou la d'acusar Trans-Atlantyk de novel-la antipatriòtica. Segons molts polonesos, Gombrowicz era un renegat que en el seu llibre no feia més que atacar el país i les seves costums (evidentment a aquests fiscals no els passava pel cap l'idea de qüestionar certs costums). Foren molts els intel-lectuals i escriptors a l'emigració que es posaren a desqualificar públicament Gombrowicz (Straszewicz, Lechoń...). Per a l'autor, l'únic que això demostrava era que la novel·la no s'havia entès bé, fins i tot entre alguns sectors de la inteliguentsia a l'exili. La majoria dels lectors no havia arribat al moll de l'os de l'al-legoria nacional, que era la càrrega de dinamita que portava la novel-la. Aquest punt resulta important si volem desentrellar quin és el lector ideal (o potser seria millor dir possible) de Trans-Atlantyk, ja que ens adonem que el ser polonès no sembla l'únic requisit indispensable per a entendre l'obra.

Una altra crítica freqüent que revé Gombrowicz fou la dels qui consideraven Trans-Atlantyk com a document anacrònic i desfasat, amb l'agreujant de ser una obra, a més a més, irritant. Efectivament, Trans-Atlantyk mostra una polonitat i uns polonesos d'abans de la Segona Guerra Mundial, amb duels, kuligs, i molta parafernàlia encara vuitcentista, mentre que la Polònia Popular dels anys 50 ja no tenia res a veure amb aquest món descrit a Trans-Atlantyk que, aparentment, havia mort per sempre. Llavors, encara que s'entengués correctament la novel·la, de què servia aquella crítica, per molt constructiva i benintencionada que fos? A més, s'acusava Gombrowicz (val a dir que amb certa innocència...) de viure en el passat i de no adonar-se que amb els comunistes les coses havien canviat, i molt. En una carta personal adreçada a Gombrowicz, Czesław Miłosz escriu:

De tant en tant tinc la sensació que actua (vostè) com Don Quixot, que donava una mena de vida als molins de vent $\mathrm{i}$ als bens. Contemplats des de la perspectiva del país (o, en 
termes generals, des de la perspectiva de l'estomacada que hem rebut), 'els polonesos' que vostè prova d'alliberar de la polonitat no són més que pobres ombres amb una existència gairebé reduïda a no res... Altrament dit, de vegades vostè es comporta com si el que tots sabem d'allà, de Polònia, aquella anihilació tan terriblement eficaç, mai no hagués existit; com si un cataclisme lunar hagués arrasat Polònia i després vingués vostè amb el fàstic que li fa la Polònia immadura i provinciana d'abans de 1939. Potser sí que té sentit, i fins i tot és necessari, que cadascú faci justícia pel seu compte; sols que, al meu parer, massa gent d'allà ha estat ajusticiada. I molts problemes han perdut la seva justificació del tot. Es un dilema molt difícil, que consisteix en el fet que el marxisme liquida (com ara la destrucció d'una ciutat destrossa els conflictes matrimonials, la preocupació pels mobles, etc.) (Gombrowicz 1999: 36).

La reflexió de Miłosz era d'esperar. Una primera lectura de Trans-Atlantyk pot portar a conclusions similars, perquè realment la Polònia d'abans de 1939 i la de després de 1949 s'assemblaven ben poc i pot donar la sensació que Gombrowicz, aïllat en una altra perifèria (geogràficament parlant, fins i tot més perifèrica...), no s'adonava realment del que estava passant a Europa. Gombrowicz es defensà al-legant que Trans-Atlantyk no parla d'una Polònia (a la qual no vol fer canviar) o d'una polonitat concretes, sinó de la Polònia eterna, de l'essència del ser polonès. Això pot sonar a defensa barata i poc fonamentada, ja que com a existencialista que era, com podia Gombrowicz parlar "A través de la Polònia del 1939, [...] de totes les Polònies actuals i futures" (Gombrowicz 1999: 37)? No obstant, el temps li ha donat la raó. Res més a prop de la realitat que aquestes paraules amb que Gombrowicz contesta a Miłosz. El comunisme, "aquella anihilació tan terriblement eficaç", canvia potser les formes, en certa manera, potser també la cultura material, però passa pel costat de l'esperit polonès (possiblement no es pot dir el mateix de Rússia). Quan el 1989 s'ensorra el mur de Berlin i amb ell tot el miratge socialista, Polònia buscarà (no cal dir que trobarà, perquè sempre foren allà) els seus referents en el catolicisme i el nacionalisme històric (el complex d'inferioritat disfressat d'autocomplaença sàrmata), tornant en certa manera... a Mickiewicz. Així, Trans-Atlantyk es llegeix avui amb tota frescor i actualitat; i si alguna vegada, si de cas d'aquí a molts anys, aquesta polonitat comença a escapçar-se alliberant l'individu, només llavors podrem parlar de Trans-Atlantyk com a artefacte històric (amb un lloc definit en el temps i l'espai) i definitivament desfasat. Finalment, només afegir que si algú acusés aquesta obra d'això, de no tenir valor fora d'un lloc i un moment concrets, només caldria adduir el seu increible valor artístic i la universalitat psicològica de moltes de les escenes narrades.

Quan Trans-Atlantyk es publica el 1957 a la República Popular de Polònia ja no aixecarà tantes passions. Potser sí que al cap i a la fi la Polònia socialista ha canviat força i la novel-la està destinada a irritar més aviat l'emigració polonesa a Occident, verdadera continuadora del país que Gombrowicz havia deixat el 1939. L'escriptor es lamenta al Testament: “D'alguna manera la van anar paint. Ningú es va prendre aquelles rareses seriosament. Ningú s'adonà de la 
dinamita que portava" (Gombrowicz 1996a: 103). Potser sigui així, ja que entre l'emigració indignà com a crítica, mentre que al país es rebé amb més lleugeresa, però tampoc s'entengué com l'autor desitjava. Representava en tot cas una gran alenada d'aire fresc respecte a la seriosa literatura que propugnava el règim. Hi hagué fins i tot algun crític que hi veié una crítica a la Sanacja, la dictadura de dretes polonesa d'abans de la guerra. De totes maneres no era res d'allò el que buscava l'autor. Ja anava bé que el pamflet irrités l'emigració, però el seu missatge profund havia d'arribar a qualsevol polonès i sobretot fer canviar el rumb de la literatura i de la intelliguentsia poloneses.

D'altra banda, molts intel-lectuals, tant de dins com de fora del país, dels pocs que entengueren l'obra, li retreien a l'autor la falta de seriositat. Si TransAtlantyk contenia un programa tan important, com podia presentar-se sota una forma tan satírica, esbojarrada i cruel? Segons molts, Gombrowicz no tenia dret a tractar un tema tan delicat i en un moment tan delicat com aquell, en una obra literària d'aquelles característiques, per més bones que fossin les seves intencions. Però quina innocència i quina serietat la d'aquells vells intel-lectuals polonesos! Ja que el que fa de Trans-Atlantyk una obra única en la historia de la literatura, més encara que la seva excepcional forma lingüística i la gran riquesa de significats, és el fet d'haver convertit en una gran riallada alliberadora el martiri nacional en el seu moment més greu.

Quant a l'acceptació i comprensió de que gaudí la novel·la a l'estranger, malauradament no hi ha massa informació per la que és segurament la obra més desconeguda de Gombrowicz fora de Polònia. Encara que actualment existeixen una dotzena de traduccions, fins fa pocs anys, només n'hi havia quatre. A més, la dificultat excepcional de la traducció i el poc coneixement de la història polonesa així com de molts dels estereotips culturals que hi apareixen, només poden augurar els pronòstics més pessimistes pel que fa a una mínima (no diguem òptima) comprensió del text per part del lector nopolonès. No obstant, el lector occidental també es pot divertir en una lectura més literal d'aquesta esbojarrada i desenfadada obra. Com hem indicat més amunt, són molts els nivells de lectura que aquesta novel-la ofereix. En tot cas, resulta molt representatiu contrastar com s'enfoquen els pròlegs de les edicions de Trans-Atlantyk en diverses llengües. Donem, doncs, una ullada a les versions més històriques.

L'edició actual polonesa de Wydawnictwo Literackie, que és l'editorial que ha gaudit des del principi dels drets d'edició de l'obra a Polònia, ve presentada amb un assaig de l'escriptor i professor de la Universitat de Gdańsk Stefan Chwin, a part del pròleg de l'autor a la primera edició nacional (la de 1957). L'anàlisi, ja canònic, de Chwin titulat "Gombrowicz i la Forma polonesa" funciona com a guia de lectura per al lector polonès mitjà, tot i que encara tot l'estudi cap a la "Forma" nacional de la novel·la. Tot en aquest estudi és anàlisi del seu programa, tot en ell és Polòia. Realment Chwin no veu cap sortida a la novel-la fora de l'àmbit nacional? Sí que n'hi veu, però pel que sembla aquesta 
es limita a la crítica al nacionalisme i al complex d'inferioritat cultural de les nacions perifèriques, preferentment aquelles de l'Europa Central i de l'Est que comparteixen certes característiques històriques amb Polònia. Quant a les múltiples interpretacions a que dóna peu el text, Chwin només es concentra en aquelles que desemmascaren referents nacionals $i$ aquelles que analitzen d'alguna manera l'esperit nacional. Per exemple, posa força èmfasi a la masculinitat i l'homofòbia de l'heroi estereotípic mickiewiczià (i nacional), encarnat en la figura de Tomasz i les seves preteses tendències homosexuals evidentment amagades i repudiades. Chwin dona tantes voltes al tema nacional que s'oblida d'altres aspectes importants d'aquesta riquíssima obra. Per exemple, és revelador el poc èmfasi que posa a l'aspecte vivencial que també té Trans-Atlantyk, i s'esforça en deixar clar que protagonista i autor comparteixen poc més que nom i cognom, sense adonar-se que Trans-Atlantyk és també Witold Gombrowicz escrit amb majúscules (d'altra banda com la resta de les seves novel-les). Sigui com sigui, aquest estudi sembla marcar el camí interpretatiu que tot lector polonès hauria de seguir.

El pròleg a l'edició francesa de Constantin Jeleński (Kot), amic personal, traductor i profund coneixedor de Gombrowicz i la seva obra, es concentra en quelcom del tot diferent. Jeleński comenta aspectes més generals de la literatura de l'autor i molt especialment la importància de la seva figura com a motor literari. Entre d'altres coses analitza l'obra en clau de memòries, encara que es tracti d'unes memòries molt sui generis. El que busca Jeleński és comentar tot allò de la novel·la que pot atreure al lector francès, sense oblidar, òbviament, el tema principal, el seu programa conceptual. En un text que el lector possiblement es llegirà abans de començar la novel·la, Jeleński apunta també el tema de la lluita entre l'individu i la nació i encara que no ho descontextualitza, és a dir, no li resta el caràcter intrínsecament polonès, sí que pretén una lectura més universal. Segurament s'oblida de les dificultats amb que s'anirà trobant el lector estranger a l'hora de desxifrar les metàfores farcides de referències històriques i culturals. D'altra banda, que més pot fer el pobre "Kot" davant una novel·la d'aquestes característiques? En tot cas, a la seva traducció (junt amb Geneviève Serreau) intenta conservar el caràcter polonès de Trans-Atlantyk.

En aquest sentit, la traducció al castellà de Kazimierz Piekarek i Sergio Pitol representa un pas enllà. Per començar, l'absència de comentaris, necessaris si és que es vol tenir una lectura mínimament ambiciosa de Trans-Atlantyk. L'edició d'Anagrama abans i de Seix Barral actualment només inclouen el pròleg a l'edició polonesa de 1957 que està dirigida bàsicament al lector polonès. Davant les dificultats tècniques que presenta el llenguatge de TransAtlantyk i la problemàtica nacional, Pitol i Piekarek es decanten per una traducció adaptada, que elimina pràcticament tota referència i fa impossible una lectura adequada. Si no fos per la procedència del protagonista i pels cognoms de la majoria de personatges, gairebé no ens adonaríem que la història té a veure amb Polònia. En aquesta traducció això sembla només una mera 
circumstància (la nacionalitat en qüestió sembla perfectament intercanviable amb d'altres: la txeca, russa, romanesa...). Pitol y Piekarek no intenten buscar un equivalent a l'arcaica tonalitat sàrmata del llenguatge: ho veuen com una missió impossible i opten per traduir a un espanyol més o menys standard, tot i que amb alguns neologismes. Així doncs, només el lector més implicat en el tema serà capaç d'adonar-se que a part de "Gombrowicz", el tema d'aquesta novel-la és també, però sobretot, "Polònia". Fins i tot l'error en el canvi de títol, que originalment fou traduït com a Transatlántico, denota en aquesta traducció la voluntat de netejar aquesta obra de tota connotació polonesa i deixar-hi només allò més universal, ja que, com diu l'autor, "el meu Trans-Atlantyk no és un vaixell, sinó una cosa com 'a través de l'Atlàntic'. La novel-la torna de l'Argentina cap a Polònia" (Gombrowicz 1996a: 105). Però a més, què en quedarà d'universal a part de la intel-ligència i el bon art de Gombrowicz si el lector no pot entendre el missatge de l'obra? En aquest cas, el suport a la universalitat ha de ser forçosament Polònia, com la humanitat té sempre com a suport l'individu concret. A favor d'aquesta versió espanyola, que serà la que acabaran llegint els lectors argentins, es pot dir que almenys funciona bé en la llengua d'arribada.

Fixem-nos, per acabar, en la traducció anglesa i el seu pròleg, que representa un enfocament translatològic oposat al de Pitol i Piekarek. La versió anglo-americana és la que més es fa esperar entre les grans llengües i no arribarà fins el 1994. Com ja hem dit anteriorment, la versió de Carolyn French i Nina Karsov és la més ambiciosa, encara que potser no la més reeixida. Es la que conté més para-textos diferents (glossari, nota dels traductors, guia de pronúncia, pròleg...), denotant una clara intenció de conservar al màxim possible el caràcter polonès de l'obra. També serà la versió que més buscarà la fidelitat al text original. Les traductores intenten conservar el llenguatge arcaic, barroc, emprant un anglès del s. XVII. No obstant, en el resultat final quedarà palesa la impossibilitat de traslladar la particularitat de la gawęda, menys encara com l'utilitza Gombrowicz, ni les connotacions que aquesta desperta en el lector polonès. També el pròleg del prestigiós poeta i traductor polonès establert als Estats Units Stanisław Barańczak intenta acostar d'alguna manera l'essència de l'obra al lector anglosaxó. Barańczak, que considera Trans-Atlantyk la novel·la més ben aconseguida de l'escriptor polonès, destaca la genialitat d'aquesta obra en el marc de la literatura universal en la seva lectura marcada i local (i només llavors exportable) i insta al lector a conservar el caràcter polonès de la novel·la.

Evidentment, ni Barańczak, ni Jeleński van tan lluny com Chwin o la resta de comentaristes polonesos de l'obra en la polonització d'aquesta. De totes maneres, queda clar el caràcter genuïnament polonès de Trans-Atlantyk així com les evidents dificultats de comprensió de l'obra per part del lector estranger, com d'altra banda tantes vegades afirmà el propi escriptor.

A l'assaig dedicat a Leoš Janáček titulat “Le mal-aimé de la famille”, Milan Kundera dedica una bonica frase al destí i a la valentia de les òperes del 
compositor txec, que podríem aplicar perfectament al Trans-Atlantyk de Gombrowicz, sota la condició de considerar la paraula langue en el sentit més ampli possible del terme, és a dir, com a forma però també contingut de l'expressió: “Difficile d'imaginer une plus grande accumulation volontaire d'obstacles. Ses opéras sont le plus bel hommage jamais rendu à la langue tchèque. Hommage? Oui. En forme de sacrifice. Il a immolé sa musique universelle à une langue quasi inconnue" (Kundera 1993: 228). Però concentrem-nos una mica més en l'interessant article de Kundera en el següent capítol i intentem desentrellar què porta Gombrowicz, com en el cas de Janáček, a immolar el seu art universal consagrant-lo, com tan clarament passa a TransAtlantyk, a la seva petita nació.

\section{SORTIR (O NO SORTIR) A LA FOTO DE FAMÍLIA}

Sigui com sigui, fou en aquest vaixell que vaig tornar a Polònia. S'havia acabat el temps del meu exili (Gombrowicz 1997a: 29).

Tot i que Witold Gombrowicz i Milan Kundera tenen poc en comú com a escriptors, els seus destins comparteixen una sèrie de característiques que els acosten. Ambdós són escriptors eslaus occidentals (pertanyen per tant a una perifèria semblant) que han conegut en pròpies carns el drama (i l'alliberació!) de l'emigració. Ambdós són primordialment novel-listes i assagistes, la obra dels quals busca sempre, encara que per camins diferents, la innovació i l'autenticitat estètiques. Encara que les seves formes d'expressió no poden estar més allunyades, quant als continguts, aquests sovint s'acosten: els dos introdueixen a la seva obra una gran càrrega filosòfica, centrant sovint els seus discursos en la inserció de l'individu a la realitat i la influència que les estructures superiors com la nació, els esdeveniments històrics o la societat tenen sobre aquest. I encara una altra cosa els enllaça: L'interès de Kundera per l'escriptor polonès, que sovint apareix en les seves reflexions sobre literatura.

Un dels temes recurrents en els assaigs d'aquests dos grans artistes/pensadors és sens dubte el de la situació i el destí de l'escriptor perifèric com a individu davant una sèrie de disjuntives; i també el de les literatures de nacions petites, com a entitats a la recerca d'una definició. Gombrowicz tractà àmpliament aquest tema als seus Diaris, però també a Trans-Atlantyk. En un dels assajos dels Testaments trahis de Kundera apareix també el problema de la situació en el mapa vertical de les literatures (local, nacional, europeu...) del gran artista relacionat amb una nació petita. Tot i que Le mal-aimé de la famille s'estructura al voltant de la figura del compositor txec Leoš Janáček, un dels exemples que treu a relluir Kundera per recolzar les seves tesis, és el de Gombrowicz. Tanmateix això no és més que una petita circumstància; l'article en sí resulta molt interessant com a base teòrica per a analitzar el cas de qualsevol artista de característiques semblants. 
Però fixem-nos una mica en l'article. Partint de l'afirmació de la genialitat de Janáček i dels valors universals de la seva música, l'escriptor es pregunta fins a quin punt és coneguda l'obra de l'autor de Jenufa al gran mercat occidental (és a dir, al centre). Tot i que gràcies a les seves innegables qualitats el compositor txec ha sortit a la llum al gran món, és poca i mal coneguda la seva genialitat. Kundera es qüestiona a més el retard de la seva acceptació mundial i arriba a la conclusió que la causa és la pertinença de l'artista a una nació petita, però sobretot l'adscripció d'aquest a l'àmbit de la cultura nacional. En primer lloc, Leoš Janáček era moravià i per tant ciutadà d'una petita nacionalitat dintre el multinacional Imperi Habsburg; en segon lloc, era nacionalista txec i paneslavista, i consagrà el seu art (el seu art gran i universal) al servei del poble, cosa que el reduiia encara més a un àmbit local; però segons Kundera el major problema quant a l'acceptació del seu art era el d'ésser un artista avançat al seu temps i, per tant, poc comprès pels compatriotes, ancorats encara a finals del s. XIX a una cultura tradicionalista i perifèrica, hereva de 1848. La tragèdia de Janáček fou, per tant, per una banda la condemna de restar incomprès i menyspreat al propi país per la innovació i la universalitat de la seva música i, per altra banda, la reclusió per part de la "Gran Cultura" a l'adscripció en el context de la "cultura nacional" com a compositor folklorista, de temàtica eslava, etc. A casa fou "le mal-aimé de la famille"; a fora, al gran món, mai se li permeté sortir de la "grande photo de famille nationale" (Kundera 1993: 233). D’aquí el mal coneixement i el retràs en l'acceptació de la seva música universal.

Fixem-nos ara en el cas de Gombrowicz i la particularitat del destí del seu art. Al seu assaig Kundera, citant a Lakis Proguidis (Proguidis 1989), afirma que la Història de la Literatura polonitza Gombrowicz, els seus comentaristes estrangers "le repoussent en arrière dans le petit contexte national" (Kundera 1993: 234), mentre que se'l priva del "gran context" de la novel.la contemporània universal, que és el que li pertoca si volem entendre el seu art i la seva novetat. Al nostre entendre, l'última asseveració és certa, encara que només parcialment. Si agafem per exemple una obra com Trans-Atlantyk (i no és pas l'única), a més de considerar-la dins el context de la novel·la del s. XX, és imprescindible també que analitzem el seu pes específic dins la Història de la Literatura Polonesa. Si agafem només allò que en principi és universal de TransAtlantyk, si ens fixem en forma i contingut sense buscar les fonts que les motiven i que en el cas d'aquesta novel-la es troben molt clarament inscrites en aquest petit context, no ens adonarem de la gran riquesa d'aquesta obra. Si un intel-lectual occidental es posa a definir el lloc de Trans-Atlantyk en la literatura europea moderna, sense fixar-se molt bé en tot el que hi ha de concretament polonès, pot fàcilment arribar a la conclusió que Trans-Atlantyk és una obra grotesca com el que ja es feia a principis de segle, només que escrita a finals dels anys 40 . Només un estudi molt detallat de l'original pot definir, per tant, la gran 
novetat i la originalitat irrepetible (irrepetible precisament pel seu caràcter marcat i local) que representa Trans-Atlantyk.

D'altra banda, sembla excessiu parlar d'una constant "polonització" de Gombrowicz. Pel que fa al món hispànic, sembla ser més aviat el contrari. Segurament pel fet d'haver viscut tota la vida d'adult lluny del seu país, a vegades dona la sensació de que quan es parla de Gombrowicz des de l'Argentina o altres llocs d'Hispanoamèrica, se'l tracta com a gran escriptor modern deslligat de tota tradició nacional (una possible adscripció argentina rarament entra en joc), com a personalitat molt específica, deslligada d'una literatura nacional on es troba tot el marasme de petits escriptors desconeguts per Occident (i per tant dolents, poc universals). Em sembla també que una gran part del món intel-lectual argentí i espanyol el considera com a un escriptor que està molt per sobre dels temes i la vida de la seva petita pàtria; un apàtrida voluntari, un artista únicament universal; una espècie de Conrad que, però, segueix escrivint en polonès. Però no s'oblida sovint la història personal de l'escriptor, la seva voluntat i el seu destí? Observem-ho, sisplau, més de prop...

Gombrowicz es converteix en exiliat/emigrat als 35 anys. L'escriptor polonès mai amagà l'alleujament que li causà, a pesar de tot, l'esclat de la guerra i l'oportunitat de realització personal que el seu aillament a l'Argentina comportà. Com expressa en nombroses ocasions, l'exili és un estat ideal per a l'escriptor, encara que no pas per perdre tot lligam amb la pàtria, sinó per a distanciar-se d'ella. En aquest sentit, Gombrowicz es mostra radicalment diferent a un gran nombre d'escriptors exiliats pels quals l'exili és un motor creatiu sobretot pel fet de constituir una tragèdia personal. Com apareix a l'assaig de Kundera, també Joyce, Ibsen, Strindberg i d'altres escriptors de nacions petites van haver de viure una llarga temporada a l'estranger per a alliberar-se dels lligams que els imposava la gran família nacional. El propi Kundera, tot i que escapava per altres raons de la pàtria, troba també la llibertat total d'expressió a l'emigració francesa. De totes maneres, anem amb compte, doncs Gombrowicz busca la distància envers la nació, però no la superació d'aquesta. Un cop a l'Argentina, i sense cap mena de pressió ni exigència per part de Polònia, Gombrowicz no es desentén pas de la literatura polonesa. Més aviat al contrari. Si ens fixem en el Kundera assagista (encara que sigui emmarcat en alguna novel·la), veiem que el seu ull crític, assentat físicament a París, es troba al centre de la literatura universal, els autors que tracta són sempre universals, el seu judici és sempre universal. Gombrowicz en canvi segueix voluntàriament lligat a la seva literatura nacional. Tant en els seus Diaris com en les cartes a altres escriptors parla amb molta més freqüència d'autors polonesos (que per a la gran Literatura no representen gran cosa) que de les grans figures internacionals, com fa Kundera. I, cosa curiosa, que no és potser la literatura rioplatense, almenys pel que fa a la prosa, una de les més suggerents i originals del segle XX? Com és que al llarg de la seva obra trobem 
tan poques referències crítiques a la literatura argentina i els seus grans noms? Potser sí que fou cosa del destí que, a pesar de la seva voluntat inicial, no li fos possible progressar en la literatura argentina, però el que resulta clar és que Gombrowicz es venjà amb una indiferència similar, gairebé programàtica, i mai es prengué massa seriosament la possibilitat de formar-ne part. D'altra banda, no es llençà a escriure en una llengua amb més sortida com el castellà (o ni que fos en francès), com feren molts d'altres, tot i que segurament li hauria estat molt més profitós: 24 anys a l'Argentina no és precisament poc. Tampoc variarà la seva temàtica ni la localització de les seves obres, que serà pràcticament sempre a Polònia.

Fent malabars amb les circumstàncies i patint un gran aïllament Gombrowicz aconsegueix conservar sempre una llibertat total, tant respecte a les exigències de la literatura i la intel-liguentsia poloneses, com a la temptació del Gran Món (de París i Buenos Aires). Tot i que lluita per ser traduït i fa grans esforços per conquerir la glòria internacional, Gombrowicz no perd mai la seva subjectivitat. Aquesta és, entre d'altres, una de les raons que li impedeixen tornar al seu país natiu: Gombrowicz no es vol arriscar a perdre la seva llibertat creativa. L'autor de Ferdydurke mai va ser taxatiu quant a la pròpia nacionalitat. Probablement la pàtria de Gombrowicz s'acabava a la pròpia pell, tot i que en aquesta petita pàtria corporal es parlava, o millor dit, s'escrivia, en polonès. Així que sí, Gombrowicz efectivament busca ser universal, però ho busca a través del que és local. Polònia és doncs la forma del seu contingut.

Però com ha estat acceptat a cada història de la literatura nacional amb la que s'ha topat Gombrowicz? Ha pagat a Polònia el preu del seu atreviment i de la seva originalitat, com li passà a Janáček a Bohèmia? Només en certa manera. Gombrowicz tenia massa talent per ser rebutjat. Pagà per la novetat de les Memòries del temps de la immaduresa, pagà per l'originalitat de Ferdydurke, pagà cara la gosadia de Trans-Atlantyk, però mai sél oblidà i cada cop que li feien la pell, sortia més fort i més ben parat. Quan durant el breu Desglaç polonès s'editen i es reediten les seves obres, el frescor, el joc, l'esperit rebel i el gust per la polèmica gombrowiczans són rebuts amb entusiasme i alegria pels intel-lectuals i lectors en general. No cal dir que encara avui té una llarga llista de detractors que no entenen la seva raresa, que el consideren un traïdor a la pàtria o que simplement no suporten la seva cara dura, però ara Gombrowicz és un autor de referència obligada.

No es pot dir el mateix de l'Argentina. País construït a partir de centenars de petits països personals emigrats, "yanquis del sur", tot nou emigrant passa ràpidament a convertir-se en ciutadà. No obstant, Don Witoldo passa mitja vida a Buenos Aires sense pena ni glòria (les batalles per la glòria es lliuraven al correu transoceànic). Tradueix Ferdydurke i El Casamiento al castellà i anys més tard, tot reunint fragments, construeix el Diario argentino ad hoc per al seu país d'adopció. No obstant, serà només als anys 60, quan abandona el país pamper, que comencen a arribar -tímidament- alguns ecos de la seva fama a Europa. 
Actualment, el públic lector argentí segueix sense conèixer massa bé ni la seva figura, ni molt menys la seva obra, i Gombrowicz és poc més que un misteriós autor de culte al país del Plata.

D'altra banda, uns pocs escriptors han intentat repescar la seva figura i introduir-lo al cànon nacional. Ricardo Piglia el va declarar "el mejor escritor argentino del siglo XX" (Piglia 1986). La frase té una vocació clarament polèmica, però tant ell com Juan José Saer han considerat Trans-Atlantyk com a una de les millors novel-les escrites a l'Argentina (Saer 2004). Sembla clar que una obra com Trans-Atlantyk té poc més d'argentina que precisament el fet d'haver estat escrita i situada a Buenos Aires i rodalies. Sigui com sigui, Gombrowicz s'estimava profundament l'Argentina i segurament l'haurien alegrat aquestes consideracions d'alguns dels grans escriptors argentins de les últimes dècades.

I finalment arribà a la terra promesa... Desprès de molts esforços, però sense rendir-se mai, conscient de la seva genialitat a escala universal, però sense trair mai el seu art per a assolir més fama, Gombrowicz es tradueix a multitud de llengües als anys $60(70,80,90 \ldots)$ i se'l reconeix ja de vell com el gran escriptor que és. Aturem-nos un moment: quins són els pocs escriptors polonesos que han fet carrera a fora? Sienkiewicz era un gran escriptor de bestsellers i amb Quo Vadis? es convertí en un èxit editorial a escala mundial. Les seves obres segueixen reeditant-se, però era poc més que un escriptor de masses i avui en dia fora de Polònia pocs recorden el seu nom; així que Sienkiewicz no compta. Schulz morí jove, amb una obra escassíssima i a més poc coneguda, ni a Polònia. Però fora d'ella tenia un cosí famós a Praga. Kafka agafa el cosinet de la mà i tots dos, els nois jueus introvertits i genials, turmentats per la figura del pare, es llancen a una passejada post-mortem pel gran món. En lloc dels argentins, a Schulz se'l disputen els israelites; els ucraïnesos comencen a estarhi interessats... Miłosz: un déu de moltes cares en la Història de la literatura polonesa, protagonista d'almenys tres èpoques de la cultura d'aquest segle. Durant els anys 50 representa el pont ideal entre Occident i el bloc comunista. Fou l'intel·lectual més hàbil sobre la corda fluixa. Rep el Nobel per la seva lírica. També el Nobel a Szymborska internacionalitza aquesta meravellosa poetessa i confirma la poesia polonesa com una de les grans tradicions poètiques del globus. Mrożek està per consagrar-se. Una brillant i refinadíssima crítica al comunisme i a la societat actual. Irònic, divertit i molt intel-ligent. Lem: cada vegada més llegit i millor, tot i que reclòs encara en el terreny de la ciència ficció. Sens dubte Kapuściński, el "reporter llegendari", però aquest reclòs en el camp del periodisme, de la no-ficció. Al costat de tots ells, Witold Gombrowicz segueix sent "l'escriptor d'escriptors" polonès per excel-lència. I tanmateix, sense parents famosos (Schulz), ni premis Nobel (Miłosz, Szymborska), sense ser políticament necessari (Mrożek), ni molt popular (Sienkiewicz, Lem, Kapuściński). Evidentment no pretenem en aquesta frase menysprear el talent dels escriptors esmentats, sinó deixar clar que per a un autor de llengua 
desconeguda com el polonès, amb el relegament a la perifèria cultural que això comporta, sovint no n'hi ha prou, com deixa entendre Kundera, amb la pròpia genialitat per a conquerir París. Com aconsegueix doncs arribar Gombrowicz, escrivint en polonès des de Buenos Aires, al panteó de la Literatura Universal? Per una banda, amb grans esforços, confiança en la pròpia vàlua i tota la voluntat del món. Però per sobre de tot gràcies a la seva excepcionalitat com a artista i al compromís amb la seva obra. Gombrowicz pot considerar-se un orgull per a les cultures petites, doncs representa el triomf de l'art, de l'entrega a l'art a pesar de tot: la immolació en sacrifici de la seva música universal va ser escoltada pels déus.

\section{BIBLIOGRAFIA}

BARAŃCZAK, S. (1997), "Forword", Gombrowicz W., Trans-Atlantyk, New Haven and London, Yale University Press.

CHWIN, S. (1996), "Gombrowicz i Forma polska”, Gombrowicz W., Trans-Atlantyk, Kraków, Wydawnictwo Literackie.

Colonna, V. (2004), Autofiction et autres mythomanies littéraires, Paris, Ed. Tristram.

Gombrowicz, R. (1991), Gombrowicz w Argentynie. Świadectwa i dokumenty 1939-1963, Wrocław, Wydawnictwo Puls.

Gombrowicz, W. (1976), Trans-Atlantique, Paris, Denoël.

GOMBROWICZ, W. (1986), Transatlántico, Barcelona, Editorial Anagrama.

Gombrowicz, W. (1996a), Testament. Rozmowy z Dominique de Roux, Kraków, Wydawnictwo Literackie.

Gombrowicz, W. (1996b), Walka o stawę. Korespondencja Witolda Gombrowicza z Józefem Wittlinem, Jarosławem Iwaszkiewiczem i Arturem Sandauerem, Kraków, Wydawnictwo Literackie

GombrowicZ, W. (1996c), Trans-Atlantyk, Kraków, Wydawnictwo Literackie.

GOMBROWICZ, W. (1997a), Dziennik 1957-1961, Kraków, Wydawnictwo Literackie.

GombrowicZ, W. (1997b), Trans-Atlantyk, New Haven and London, Yale University Press.

GOMBrowicZ, W. (1999), Dietari (1953-1956), Barcelona, Edicions 62.

JARZĘBSKI, J. (1981), “Być wieszczem”, Teksty, Warszawa.

JelEŃSKI, C. (1976), "Préface”, Gombrowicz W., Trans-Atlantique, Paris, Denoël.

KunderA, M. (1993), Les testaments trahis, Paris, Editions Gallimard.

PigLia, R. (1986), Crítica y ficción, Santa Fe, Universidad nacional de Santa Fe.

PROGUIDIS, L. (1989), Un écrivain malgré la critique, Essai sur l'oeuvre de Witold Gombrowicz, Paris, L'infini.

SAER, J. J. (2004), El concepto de ficción, Buenos Aires, Seix-Barral. 